\title{
APONTAMENTOS SOBRE A FORMACÃO DOCENTE EM NÍVEL MÉDIO NO ESTADO DO RIO DE JANEIRO
}

\author{
Notes on teacher training at secondary level in the state of Rio de Janeiro \\ Notas Sobre los Profesores de Formación en Nivel Medio en Rio de Janeiro \\ Laélia Carmelita Portela Moreira ${ }^{1}$ \\ Débora Borges Lima ${ }^{2}$
}

\begin{abstract}
RESUMO: O presente artigo discute formação inicial de professores em nível médio, Curso Normal, no Estado do Rio de Janeiro, a partir de uma reflexão baseada na abordagem do ciclo de políticas. Analisa a materialização, no contexto da prática, da previsão do artigo 62 da Lei 9394/06 de elevação da formação de professores para o nível superior e do prazo de 10 anos para a extinção do Curso Normal, com base na coexistência, no estado em tela, da formação docente para os anos iniciais do Ensino Fundamental, no curso Normal e no Curso de Pedagogia. Após breve contextualização das políticas de formação e da trajetória do curso Normal apresenta-se a situação do Rio de Janeiro problematizando-se, com base na metodologia do ciclo de políticas, a ressignificação dessa política de formação de professores e sua incorporação aos Sistemas de Ensino.
\end{abstract}

Palavras chave: Formação de Professores. Curso Normal. Ciclo de políticas.

\section{INTRODUÇÃO}

A melhoria da qualidade da educação constitui temática amplamente discutida nas últimas décadas, no Brasil, e tal noção tem norteado projetos e programas de um modo geral, e, particularmente, as políticas de formação de professores, destacadas como um dos fatores que contribuem para o êxito da educação no país. Historicamente essa problemática e as disputas em torno de diferentes concepções de formação docente têm sido marcadas por dois movimentos que se encontram, nem sempre de forma harmoniosa: de um lado as forças que impulsionam reformas educacionais pautadas pelas necessidades econômicas e anseios políticos correspondentes, e, de outro, as propostas dos educadores, as quais marcaram momentos importantes na construção dessa história através de reivindicações coletivas construídas nos debates.

Este artigo apresenta uma análise da formação inicial de professores no Curso Normal e nível médio. Tem como objetivo problematizar o descompasso entre a previsão da elevação da formação de professores para o nível superior, contida no artigo 62 da Lei de Diretrizes e

\footnotetext{
${ }^{1}$ Doutora em Educação pela Universidade Federal do Rio de Janeiro. Professora adjunta do Programa de PósGraduação em Educação da Universidade Estácio de Sá (PPGE/UNESA). Linha de Pesquisa: Políticas Gestão e Formação de Educadores. E-mail: moreira.laelia@gmail.com.

${ }^{2}$ UNESA Mestre em Educação pelo PPGE/UNESA e professora da rede municipal de Duque de Caxias e da SEEDUC RJ. E-mail: debora.limaaaa@gmail.com.
} 
Bases da Educação Nacional (LDBEN/9.394/96), e a consequente extinção do Curso Normal no prazo de dez anos, e o contexto da prática, considerando-se a permanência do Curso Normal, que ainda existe e resiste num cenário político e legal quase totalmente delineado para uma formação docente em nível superior.

O artigo está estruturado em três partes. A primeira, constituída pela apresentação dos conceitos gerais e da abordagem do ciclo de políticas, a segunda parte, que trata das políticas específicas da formação de professores e, por último, a apresentação da situação do Curso Normal no Estado do Rio de Janeiro.

\section{A PESQUISA EM POLÍTICAS PÚBLICAS COMO UM CAMPO EM CONSTRUÇÃO}

Como subárea da ciência política, o campo de estudo das políticas públicas se consolidou somente a partir da década de 1950, quando estas passaram a ser consideradas como objeto de análise, pois anteriormente como sinaliza Faria (2003, p. 21), a ciência política analisava a política pública “[...] como um output do sistema político, e justificava a concentração da linha de investigação sobre os inputs do sistema, em suas demandas e articulações de interesse.”.

Segundo Souza (2006), no cenário inicial das políticas públicas, destacam-se quatro autores que se sobressaem, naquele momento, pelo modo inovador como tratam esse campo de conhecimento. Laswell, que traz o conceito de análise de políticas públicas buscando relacionar o conhecimento científico com a ação do governo. Simon, que sustenta o conceito de racionalidade vinculada às decisões políticas. Lindblom, que de forma inovadora propõe a incorporação de novas variáveis à análise de políticas públicas, tais como a integração entre as diferentes fases do processo decisório, o papel das eleições, das burocracias e ainda dos partidos e grupos de interesses. E, por último, Easton, que traz como contribuição a definição das políticas públicas como um sistema, ou seja, “[...] como uma relação entre formulação, resultados e o ambiente. Para esse autor, as políticas públicas recebem inputs de vários sistemas como os partidos, a mídia e os grupos de interesse, e esses influenciam seus resultados e efeitos" (SOUZA, 2006, p. 24).

Pode-se dizer que, na atualidade, o campo de pesquisa dedicado à área das políticas públicas vem se desenvolvendo amplamente, impactado pelas próprias mudanças da sociedade. No entanto, a literatura aponta inúmeras críticas quanto à solidez dos estudos sobre

Revista de Ciências Humanas | FW | v. 15 | n. 24 | p. 33-46 | Jul. 2014 
este assunto, não apenas em seus aspectos gerais (SOUZA, 2003; 2006), quanto no que se refere à pesquisa em políticas educacionais.

Mainardes (2006; 2009) e Aguiar e Azevedo (1998), dentre outros, têm apontado a necessidade de maior consolidação dessa área de investigação, caracterizada por muitos estudos horizontais sobre casos específicos, falta de interlocução com a literatura internacional e ainda com a bibliografia do campo da Ciência Política e das Ciências Sociais, embora a institucionalização desse campo tenha se iniciado a partir do final da década de 1960 “[...] por meio da utilização do termo 'política educacional' e 'políticas educacionais' em títulos de teses, dissertações, artigos e publicações oficiais" (MAINARDES; GANDIN, 2013, p. 144). Entretanto, apesar do aumento de textos referentes aos processos decisórios, é consensual a constatação da ausência, no campo educacional, de estudos que focalizem os diversos contextos de implementação.

A definição do que é política, e especificamente do que é política pública demanda análise de como ela é estudada e pela consideração que ela não é um fim, mas sim um meio; não pode ser considerada uma decisão isolada, mas antes um conjunto de decisões e definições de estratégias, e, talvez por esse motivo, apresente múltiplas possibilidades de interpretação. Assim, as políticas públicas não podem ser compreendidas somente pelas realizações do Estado, mas também nas lacunas deixadas por ele (SERAFIM; SILVA, 2012). Seu estudo exige abordagens multidisciplinares, visto que repercutem na economia e nas sociedades. A aceitação de uma visão holística sobre a política pública, segundo Souza (2006) facilita a compreensão do uso de distintos modelos analíticos ou de várias abordagens, já que se torna necessária a interlocução com outras áreas de conhecimento.

\section{A TEORIa do CIClo DE POLíticas NA ANÁlise DE POLÍticas EDUCACIONAIS BRASILEIRAS}

No Brasil, a abordagem do ciclo de política a partir das ideias de Stephen Ball e seus colaboradores vêm sendo utilizada como uma ferramenta útil na análise das políticas educacionais e tem sido bastante difundida. Em recente levantamento apresentado por Mainardes e Gandin (2013) ${ }^{3}$ foi constatado que as ideias dos autores mencionados já estão

\footnotetext{
${ }^{3}$ Os dados foram apresentados durante o seminário "Diálogos com a Pesquisa - As contribuições de Stephen Ball para a pesquisa educacional no contexto brasileiro: análises e reflexões", realizado na Universidade Revista de Ciências Humanas | FW | v. 15 | n. 24 | p. 33-46 | Jul. 2014 
presentes em 128 publicações, sendo 01 livro, 12 capítulos, 40 artigos em periódicos, 26 teses e 49 dissertações.

A abordagem do Ciclo de Políticas proposta por Ball e Bowe (MAINARDES, 2006), inicialmente apresentava a noção de política como um ciclo contínuo constituído pela política proposta, política de fato e política em uso, esquema modificado posteriormente para os contextos de influência, da produção do texto e da prática e passou a contar, a partir de 1994, com uma versão mais refinada desse ciclo com a inclusão de dois outros contextos: o dos resultados (efeitos) e o das estratégias políticas.

No contexto de influência se situam as bases da política e ainda o início dos discursos políticos. É neste contexto que ocorrem as disputas, podendo a arena pública ser constituída também por grupos e comissões representativas. Na educação podemos perceber que

[...] É nesse contexto que grupos de interesse disputam para influenciar a definição das finalidades sociais da educação e do que significa ser educado. Atuam nesse contexto as redes sociais dentro e em torno de partidos políticos, do governo e do processo legislativo. É também nesse contexto que os conceitos adquirem legitimidade e formam um discurso de base para a política [...] (MAINARDES, 2006, p. 51).

O contexto da produção dos textos pode ser compreendido como a própria representação da política e, sua leitura não é estanque. No momento em que eles são produzidos atendem a determinada situação política, no entanto ao serem utilizados em outro tempo ou em outro local não terão o mesmo sentido da sua criação. Os conteúdos dos documentos são decodificados para atender à realidade dentro da qual serão utilizados, não sendo possível assimilação ou aplicação imediata (SHIROMA; CAMPOS; GARCIA, 2005). Tal apontamento confirma alguns desajustes que ocorrem entre a elaboração de textos de projetos ou ações para formação de professores, que perdem a sua finalidade ou são lidos de forma diferente, quando chegam ao contex to da prática.

Muitas vezes, durante a formulação da agenda política ocorrem várias construções de textos, que já passaram por ajustes em conferências e debates sobre determinada problemática a ser solucionada, mas ao chegar ao contexto da prática não mantêm a sua funcionalidade original. As políticas, como afirmam Ball e Mainardes (2011, p. 14) “[...] podem ser sujeitas a interpretações e traduções e compreendidas como respostas a problemas da prática [...] estão

Estadual de Campinas (UNICAMP) em outubro de 2013. Disponível em:


sempre em algum tipo de fluxo, no processo de se tornarem algo mais.” Quanto ao contexto da prática, este se relaciona diretamente com as suas possibilidades de recriação durante a execução. (BOWE et al., 1992).

A abordagem do Ciclo de Políticas oferece aos pesquisadores conceitos importantes para uma análise das políticas educacionais, facilitando o entendimento da complexidade existente. Favorece, além disso, o intercâmbio com outras fontes, por meio da análise de documentos, comparação com outros países, valorização das informações das mídias e internet, configurando múltiplos olhares sobre a situação observada. Destaque-se ainda a atenção aos processos das micropolíticas e aos diversos atores que, no contexto da prática, ressignificam e reinventam as políticas. Justifica-se, portanto, como uma ferramenta útil na análise das políticas de formação docente, as quais, muitas vezes, limitam-se ao contexto de influência, com prevalência daquelas que focalizam as ingerências dos organismos internacionais nos países da América Latina e Caribe e a análise dos textos, sem, entretanto dedicar a atenção necessária ao contexto da prática e à forma como estes são apropriados nos estados, municípios escolas e salas de aula pelos diferentes atores envolvidos no processo.

$\mathrm{Na}$ investigação sobre os caminhos percorridos pela formação de professores no Brasil, não se pode desconsiderar as lutas, ideologias e tensões internas que existem e atuam nas estruturas políticas, sociais e locais. Sob esse olhar, podemos refletir sobre políticas para a formação de professores que, no macro contexto, ante a motivação pela melhoria da qualidade na educação, preconizavam a formação docente em nível superior para todos os professores num curto prazo, conforme descrito nas Disposições Transitórias da LDBEN 9.394/96 (BRASIL, 1996). Como resultado, acreditava-se que com a formação de professores em nível superior, o Curso Normal, entraria em extinção. O que se verificou, entretanto foi que, na prática, o país de se mostrou despreparado para consolidar essa extinção, visto que a formação em nível médio ainda era a única formação possível em vários locais do país.

\section{CAMINHOS DA FORMAÇÃO DOCENTE: A RESISTÊNCIA DO CURSO NORMAL}

Sem dúvida, a proposta política de ampliação do nível de escolaridade por ocasião da promulgação da Lei 9.394/96 surgiu visando a elevação da qualidade da formação dos docentes, os quais desempenham tarefa de grande complexidade, cujo nível de exigência demanda formação inicial sólida e aperfeiçoamento contínuo (BRASIL, 1996). Essa

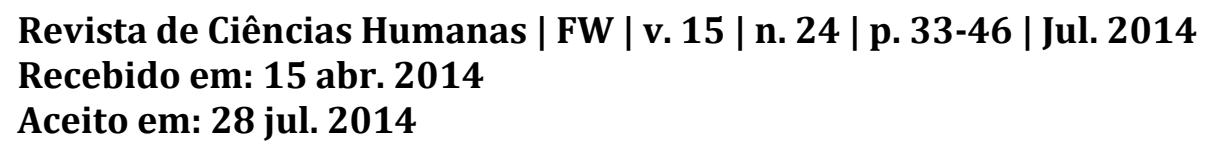


ambiguidade já mencionada só foi resolvida com a promulgação da Lei 12.796/2013, que muito oportunamente vem ao encontro da resolução de um problema crônico da educação brasileira, a saber, a existência de professores que, em determinadas regiões do país, ainda lecionam sem a formação adequada (BRASIL, 2013). Dados da Sinopse Estatística da Educação Básica de 2012, realizado pelo INEP (BRASIL, 2012), revelam que apesar da previsão legal e da consequente redução de matrículas no Curso Normal este ainda permanece como espaço de formação inicial em diversos estados do país, conforme apresentação da Figura 1.

Figura 1 - Número de alunos matriculados no Curso Normal por estado (2012)

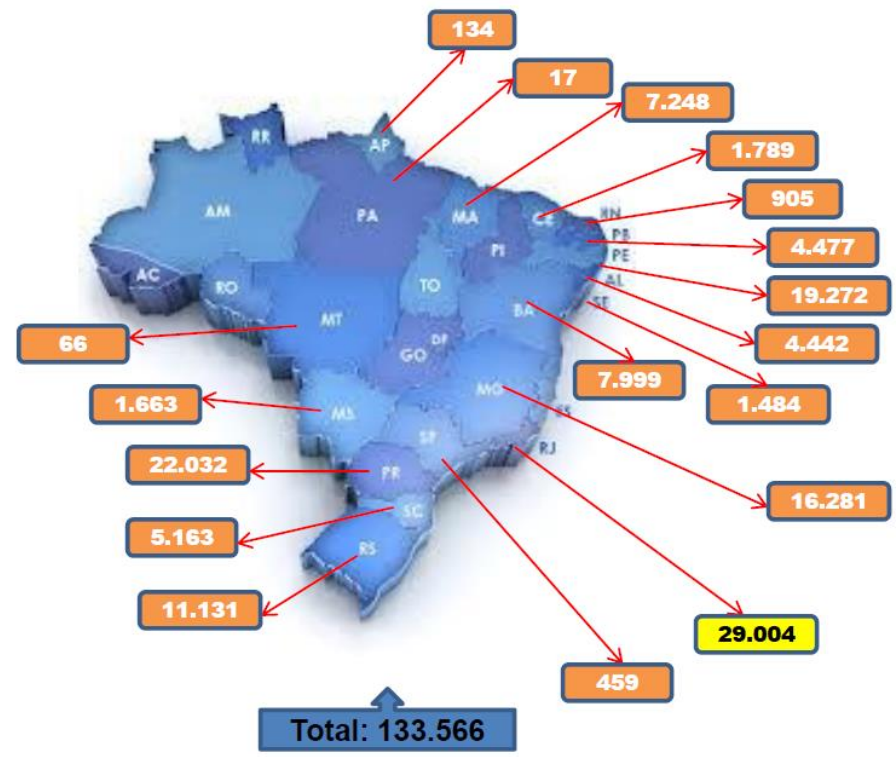

Fonte: Organizada pela autora com base nos dados do Censo 2012 (BRASIL, 2012)

Os números apresentados demonstram como a formação inicial de professores em nível médio ainda é ofertada e procurada em todas as regiões do Brasil. Como se pode observar, o estado do Rio de Janeiro apresenta maior em número de matrículas do país na formação em nível médio, com 29.004 alunos matriculados em 2012, seguido do estado do Paraná, que mantém 22.032 matrículas no mesmo ano.

O levantamento de dados históricos sobre a formação de professores em nível médio, realizado pelo Instituto Nacional de Estatística e Pesquisa (INEP) em 2003, revelou, naquele momento, que o número de matriculas nesta formação estava em constante crescimento, passando de 640.770 no ano de 1991 para 851.570 em 1996. Alguns anos depois, sob o efeito 
da nova legislação, que previa a elevação para o nível superior, ocorreu uma redução de quase 50\%, em 2002, registrando-se, nesse ano, 368.006 matrículas. (BRASIL, 2003).

No entanto, apesar da previsão legal e da consequente redução de matrículas no Curso Normal, este ainda encontra espaço em todas as regiões do país, conforme revelam os dados da Sinopse Estatística da Educação Básica de 2012, realizado pelo INEP (BRASIL, 2012), como mostra o Quadro 1.

Quadro 1 - Número de alunos matriculados no Curso Normal por região (2012)

\begin{tabular}{c|c}
\hline REGIÃO & ALUNOS MATRICULADOS \\
\hline Norte & 151 \\
\hline Nordeste & 47.616 \\
\hline & \\
\hline Sudeste & 45.744 \\
\hline Sul & 38.326 \\
\hline & 1.729 \\
\hline Centro-Oeste & 133.566 \\
\hline & \\
\hline Fonte: Organizado pelas autoras com base nos dados do MEC/Inep (BRASIL, 2012)
\end{tabular}

\section{O CURSO NORMAL NO ESTADO DO RIO DE JANEIRO}

Os números citados indicam que apesar da previsão política e legislativa para elevação do nível de formação dos professores ao patamar do nível superior, algumas localidades do país ainda precisam e dependem deste espaço para formação inicial de professores. Nessa perspectiva, visando observar como a realidade se concretiza, por meio da legislação e das políticas, focalizamos o Estado do Rio de Janeiro, que possui o maior número de matrículas e conta atualmente de um total de 29.004 alunos matriculados no curso de formação de professores em nível médio, Curso Normal, sendo distribuídos nas seguintes dependências administrativas: (a) 620 na rede privada, (b) 424 na rede municipal e (c) 27.960 na rede estadual pública de ensino (BRASIL, 2012).

As políticas instituídas pela Secretaria de Educação do Estado (SEEDUC), mesmo antes das alterações trazidas pela Lei 012.796 de 2013, já apontavam para a continuidade do curso Normal (BRASIL, 2010). Um dos exemplos foi à implantação de um novo Currículo Mínimo para o Ensino Médio, na modalidade Normal, em janeiro de 2013, planejado pela Revista de Ciências Humanas | FW | v. 15 | n. 24 | p. 33-46 | Jul. 2014 
Fundação Centro de Ciências e Educação Superior a Distância do Estado do Rio de Janeiro (CECIERJ), com a colaboração dos professores que atuavam no curso. Da mesma forma, o Plano Estadual de Educação do Rio de Janeiro, instituído em 2010, ancora a formação em nível médio, quando formula, no artigo $3^{\circ}$, como um de seus objetivos:

\begin{abstract}
Estabelecer programas de formação de profissionais de Educação Infantil, de forma que, no prazo máximo de $10(\mathrm{dez})$ anos, a partir da publicação deste Plano, os professores, auxiliares de creche, berçaristas e os dirigentes das instituições públicas e privadas possuam, no mínimo, formação de nível médio, na modalidade Normal, no âmbito do "Programa Escola-Infância", nos termos da Lei Estadual n ${ }^{\circ}$ 5.311/2008. (RIO DE JANEIRO, 2009).
\end{abstract}

Como se pode constatar, além de reforçar a continuidade do curso Normal, a proposta desse Plano define a criação de áreas de atuação mais específicas, ou seja, a Educação Infantil. Os editais de processos seletivos e concursos públicos que serão analisados que serão analisados a seguir confirmam esta tendência.

No que se refere à formação dos professores que já atuam na educação básica do estado do Rio de Janeiro, observou-se um alto número de professores com a formação apenas em nível médio, segundo dados da Sinopse do Professor da Educação Básica realizada pelo Instituto Nacional de Estudos e Pesquisas (INEP), conforme se observa na Tabela 1.

Tabela 1 - Escolaridade do professor da Educação Básica

\begin{tabular}{|c|c|c|c|c|c|c|c|}
\hline \multirow{4}{*}{ Ano } & \multirow{4}{*}{$\begin{array}{l}\text { Unidade da } \\
\text { Federação }\end{array}$} & \multicolumn{6}{|c|}{ Professores da Educação Básica } \\
\hline & & \multirow{3}{*}{ Total } & \multicolumn{5}{|c|}{ Escolaridade } \\
\hline & & & \multirow[b]{2}{*}{ Fundamental } & \multicolumn{3}{|c|}{ Ensino Médio } & \multirow[b]{2}{*}{$\begin{array}{c}\text { Ensino } \\
\text { Superior }\end{array}$} \\
\hline & & & & $\begin{array}{c}\text { Médio } \\
\text { Total }\end{array}$ & $\begin{array}{c}\text { Normal/ } \\
\text { Magistério }\end{array}$ & $\begin{array}{l}\text { Ensino } \\
\text { Médio }\end{array}$ & \\
\hline 2007 & Rio de Janeiro & 133.517 & 305 & 39.149 & 33.914 & 5.235 & 94.063 \\
\hline 2008 & Rio de Janeiro & 150.490 & 321 & 50.715 & 46.031 & 4.684 & 99.454 \\
\hline 2009 & Rio de Janeiro & 143.029 & 315 & 48.130 & 43.786 & 4.344 & 94.584 \\
\hline
\end{tabular}

Os números apontam para uma situação de desarmonia entre a formulação de uma política educacional macro e a que realmente se concretiza na realidade brasileira, ou seja, sua consolidação nos municípios e estados. Apesar da determinação estabelecida pela lei 9394/96 (BRASIL, 1996) nacional para elevação do nível de formação de professores, o que se constata é que, mesmo após mais de uma década, a promulgação da Lei não garantiu a implantação de políticas capazes de alterar o quadro de escolarização dos professores da Educação Básica.

Revista de Ciências Humanas | FW | v. 15 | n. 24 | p. 33-46 | Jul. 2014

Recebido em: 15 abr. 2014

Aceito em: 28 jul. 2014 
As informações da tabela demonstram que, entre os anos de 2007 e 2009, o nível superior não obteve um aumento significativo, apesar do número total de professores ter aumentado em quase dez mil, em contradição a realidade de ações políticas voltadas para a formação de professores em nível superior. Registra ainda o aumento do número de professores com o curso Normal/Magistério contabilizando-se uma diferença de aproximadamente dez mil entre o ano de 2007 e 2008.

Em decorrência desse descompasso instaurado no âmbito das políticas de formação inicial de professores, investigamos a situação de alguns municípios do estado do Rio de Janeiro, na tentativa de identificar o que tem sido priorizado na seleção de professores para atuarem nos anos iniciais do Ensino Fundamental.

No Quadro 2 destacamos 10 (dez) editais de processos seletivos e concursos públicos para seleção de professores dos anos iniciais e suas respectivas habilitações para concorrer ao cargo. Pode-se observar que a maioria dos municípios estabeleceu como formação mínima para ocupação do cargo de professor dos anos iniciais, a formação em nível médio, ou seja, o Curso Normal.

Quadro 2 - Formação Mínima Exigida para o Cargo de Professor dos Anos Inicias

\begin{tabular}{l|l|l|l}
\hline Ano & Edital no & Prefeitura & Formação para professor \\
\hline 2012 & $001 / 2012$ & Prefeitura de Natividade & $\begin{array}{l}\text { Ensino Médio Magistério/Normal ou } \\
\text { Normal Superior }\end{array}$ \\
\hline 2012 & $01 / 2011$ & Prefeitura de Magé & $\begin{array}{l}\text { Ensino Médio, Curso de formação de } \\
\text { Professores }\end{array}$ \\
\hline 2012 & $01 / 2012$ & Prefeitura de Belford Roxo & $\begin{array}{l}\text { Ensino Médio Completo com Curso de } \\
\text { Formação de Professores, Curso } \\
\text { normal, reconhecido pelo MEC }\end{array}$ \\
\hline 2011 & $01 / 2012$ & Prefeitura de Miracema & $\begin{array}{l}\text { Ensino Médio na modalidade } \\
\text { Magistério e/ou Normal Superior e/ou } \\
\text { Ensino Superior em Pedagogia com } \\
\text { habilitação específica }\end{array}$ \\
\hline 2012 & $029 /$ CEPU & Prefeitura de Queimados & $\begin{array}{l}\text { Curso Normal (em instituição } \\
\text { autorizada pelo Poder Público.); Curso } \\
\text { Normal Superior (para Educação } \\
\text { Infantil) ou Curso de Pedagogia (com } \\
\text { habilitação para Educação Infantil) }\end{array}$ \\
\hline 2011 & $003 /$ PMSG & $\begin{array}{l}\text { Formaçáo de Professores de nível } \\
\text { médio na modalidade normal ou curso } \\
\text { de nível superior de licenciatura plena } \\
\text { em Pedagogia }\end{array}$ \\
\hline /RJ & Prefeitura de São Gonçalo & $\begin{array}{l}\text { Curso Normal Médio ou Curso Superior } \\
\text { ou Curso de Pedagogia para Educação } \\
\text { Infantil e séries iniciais do Ensino } \\
\text { Fundamental }\end{array}$ \\
\hline
\end{tabular}

Revista de Ciências Humanas | FW | v. 15 | n. 24 | p. 33-46 | Jul. 2014 


\begin{tabular}{l|l|l|l}
\hline & & & Educação Infantil \\
\hline 2012 & $\begin{array}{l}\text { SMA N } \\
111\end{array}$ & $\begin{array}{l}\text { Prefeitura do Rio de } \\
\text { Janeiro } \\
\text { (Concurso Público para } \\
\text { provimento de cargos de } \\
\text { Professor I de Educação } \\
\text { Infantil) }\end{array}$ & $\begin{array}{l}\text { Nível Médio, na modalidade Normal ou } \\
\text { Curso Normal Superior ou Licenciatura } \\
\text { Plena em Pedagogia, com habilitação } \\
\text { para docência na Educação Infantil e } \\
\text { anos iniciais do Ensino Fundamental ou } \\
\text { específica para Educação Infantil. }\end{array}$ \\
\hline 2012 & $\begin{array}{l}\text { SMA } \\
N^{\circ} 170\end{array}$ & $\begin{array}{l}\text { Prefeitura do Rio de } \\
\text { Janeiro } \\
\text { (Concurso Público para } \\
\text { provimento de cargo de } \\
\text { Professor II) }\end{array}$ & $\begin{array}{l}\text { Curso Normal Superior com habilitação } \\
\text { em docência nos anos iniciais do Ensino } \\
\text { Fundamental, ou Licenciatura Plena em } \\
\text { Pedagogia com habilitação em docência } \\
\text { nos anos iniciais do Ensino }\end{array}$ \\
& & $\begin{array}{l}\text { Fundamental, ou Habilitação específica } \\
\text { em curso superior de graduação } \\
\text { correspondente à Licenciatura Plena } \\
\text { (Ensino Fundamental) e habilitação em } \\
\text { docência nos anos iniciais do Ensino } \\
\text { Fundamental (Curso de Formação de } \\
\text { Professores - Nível Médio). }\end{array}$ \\
\hline
\end{tabular}

Fonte: Organização própria a partir dos editais publicados - todos os editais analisados constam nas referências no final do texto.

Este panorama indica que apesar da perda de espaço e prestígio do curso Normal e das inúmeras tentativas de elevação da formação inicial de professores para o nível superior, o próprio sistema público depende desta formação inicial, ou seja, a escola normal permanece como uma das importantes instituições de formação de professores para os anos iniciais. Ressalta-se o caso específico da prefeitura do Rio de Janeiro, a maior rede pública de ensino da América Latina, que parece estar delineando o perfil do egresso do Curso Normal. Como exemplo, o lançamento do edital SMA n ${ }^{\circ} 111$ datado de 28 de maio de 2012, especificamente para professor da Educação Infantil (PEI), no qual a exigência era: (a) Nível Médio, na modalidade Normal ou (b) Curso Normal Superior ou Licenciatura Plena em Pedagogia, com habilitação para docência na Educação Infantil e anos iniciais do Ensino Fundamental ou específica para Educação Infantil.

Enquanto para a seleção de professores do $1^{\circ}$ ao $5^{\circ}$ ano de escolaridade, conforme o edital SMA nº 170 de 26/11/2012 não se admite mais o egresso do Curso Normal, mas apenas candidatos com Curso Normal Superior com habilitação em docência nos anos iniciais do Ensino Fundamental, ou Licenciatura Plena em Pedagogia com habilitação em docência nos anos iniciais do Ensino Fundamental, ou Licenciatura plena, com habilitação específica em curso superior de graduação correspondente à licenciatura plena e habilitação em docência nos anos iniciais do Ensino Fundamental. 
Relacionando os últimos editais do município do Rio de Janeiro ao Plano Estadual de Educação, acreditamos que há uma tendência para a aceitação dos alunos egressos do Curso Normal na docência da Educação Infantil, na atuação docente ou para os que atuam nesta modalidade de ensino.

\title{
CONSIDERAÇÕES FINAIS
}

A propósito das políticas educacionais direcionadas para a formação docente, Gatti, Barreto e André (2011, p. 266) em estudo realizado sobre as políticas recentes de formação de professores no país, afirmam que "[...] quanto mais complexas as políticas, maior distância se instala entre formuladores e implementadores [...] e que estes tendem a atuar segundo as suas próprias referências, ao executá-las.” Enfatizam ainda a importância de uma articulação política de ações entre os três níveis da Federação, para que haja uma verdadeira política de Estado, contemplando as diversidades das instâncias e os diferentes fatores que contribuem para a qualidade da educação no país.

No caso específico do Estado do Rio de Janeiro, a partir de 2001, foram estabelecidos vários grupos de estudos, em uma articulação entre a Secretaria Estadual da Educação do Rio de Janeiro - SEEDUC RJ e professores, para adaptação às diretrizes. Ao término do trabalho, em 2006 foi implantada a Reorientação Curricular para o Curso Normal em todas as escolas estaduais com formação de professores.

Atualmente, com o passar de mais de quinze anos, as políticas de formação de professores, após uma reinterpretação embasada no Contexto da Prática, se reinventou e em decorrência promoveu a revisão do parágrafo que previa a formação de professores em nível superior no prazo de dez anos, instituindo através da Lei n 12.796 , de 4 de abril de 2013, a sua revogação, configura-se então a permanência da formação em nível médio.

\begin{abstract}
This article discusses aspects of Initial Teacher Training (ITT) at secondary level in the state of Rio de Janeiro, arising from a reflection grounded on the policy cycle approach. The text analyses the implementation, in the context of practice, of Article 62 of Law 9394/06, which determined that, within a period of 10 years, all early years ITT should be carried out in Higher Education, signalling the end of the Normal course (secondary level) and the strengthening of the Pedagogy degree, the alternative, concomitantly existing route for ITT when the law was promulgated. Following a brief contextualisation of current training policies and pathways, as well as an overview of the characteristics of the Normal course, the situation in the state of Rio de Janeiro is examined and the reframing of state-wide policy is
\end{abstract}

Revista de Ciências Humanas | FW | v. 15 | n. 24 | p. 33-46 | Jul. 2014

Recebido em: 15 abr. 2014

Aceito em: 28 jul. 2014 
problematised with basis on the policy cycle methodology.

Keywords: Initial Teacher Training. ITT. Normal course. Policy cycle .

RESUMEN: Este artículo analiza las características de la formación inicial del profesorado de enseñanza secundaria en el estado de Río de Janeiro, a partir de una reflexión sobre las políticas públicas aplicadas. Analiza la materialización práctica, del artículo 62 de la Ley 9394/06 sobre la elevación de la calidad de la formación docente para profesores del nivel superior y sobre el plazo de 10 años para la extinción del Curso Normal, basado en la coexistencia en el Estado citado, de la formación del profesorado de las escuelas primarias, en el curso normal y en el curso de Pedagogía. Después de una breve contextualización de las políticas de formación y de la trayectoria y características del curso Normal se presenta la situación en el Estado de Río de Janeiro debatiéndose, tomando como base la metodología del ciclo de políticas públicas, el replanteamiento de esta política de formación del profesorado en el Estado de Rio de Janeiro.

Palabras clave: Formación del Profesorado. Curso Normal. Políticas públicas.

\section{REFERÊNCIAS}

AGUIAR, Márcia A. da Silva; AZEVEDO, Janete M. L. O Grupo de Trabalho Estado e Política Educacional: identidade, trajetória, perspectivas. Caxambú: ANPEd, 1998.

BALL, S. J.; MAINARDES, J. (Orgs.). Políticas educacionais: questões e dilemas. São Paulo: Cortez, 2011.

BOWE, R; BALL, S.; GOLD, A. Reforming education \& changing schools: case studies in Policy Sociology. London: Routledge, 1992.

BELFORD ROXO. Edital n. 01/2011, de 10 jan. 2012. Concurso Público - Edital nº1/2012 Provimento de cargos efetivos. Disponível em: <http://www.iesap.com.br/noticias/files/Edital_Belford_Roxo.pdf〉. Acesso em: 02 jan. 2013.

BRASIL. Congresso Nacional. Lei n. 9.394, de 20 de dezembro de 1996. Estabelece as diretrizes e bases da educação nacional. Disponível em: <http://www.planalto.gov.br/ccivil_03/leis/19394.htm>. Acesso em: 02 jan. 2013.

Ministério da Educação. Instituto Nacional de Estudos e Pesquisas Educacionais Anísio Teixeira (INEP). Sinopses Estatísticas da Educação Básica. Brasília, DF, 2003. Disponível em: <http://portal.inep.gov.br/basica-censo-escolar-sinopse-sinopse>. Acesso em: 03 dez. 2012.

Ministério da Educação. Instituto Nacional de Estudos e Pesquisas Educacionais Anísio Teixeira (INEP). Sinopses Estatísticas da Educação Básica. Brasília, DF, 2012. Disponível em: < http://portal.inep.gov.br/basica-censo-escolar-sinopse-sinopse >. Acesso em: 05 ago. 2013.

Revista de Ciências Humanas | FW | v. 15 | n. 24 | p. 33-46 | Jul. 2014

Recebido em: 15 abr. 2014

Aceito em: 28 jul. 2014 
Lei $\mathrm{n}^{\circ}$ 012.796, de 04 de abril de 2013. Altera a Lei $\mathrm{n}^{\circ}$ 9.394, de 20 de dezembro de 1996, que estabelece as diretrizes e bases da educação nacional, para dispor sobre a formação dos profissionais da educação e dar outras providências. Diário Oficial [da] República Federativa do Brasil, Brasília, DF, 05 de abril de 2013.

FARIA, Carlos Aurélio Pimenta. Ideias, Conhecimento e Políticas Públicas: Um Inventário Sucinto das Principais Vertentes Analíticas Recentes, Revista Brasileira de Ciências Sociais, v. 18, n. 51, p. 21-30, 2003.

GATTI, B.; BARRETO, E. S. S; ANDRÉ, M. E. D. Políticas docentes no Brasil: um estado da arte. Brasília: UNESCO, 2011.

MARTIS, Angela Maria. O campo das políticas públicas de educação: uma revisão de literatura. Estudos em Avaliação Educacional, São Paulo, v. 24, n. 56, p. 276-299, set./dez. 2013.

MAGÉ. Edital n. 01/2011, de 30 dez. 2011. Edital do Concurso Público n'01/2011PMM/RJ. Disponível em:

<http://www.mage.rj.gov.br/downloads/concursos/janeiro2012.pdf >. Acesso em: 02 jan. 2013.

MIRACEMA. Edital n. 01/2012, de 08 nov. 2012. Edital do Concurso Público no. 001/2012. Disponível em: 〈http://www.idecan.org.br/concursos/80/5.pdf>. Acesso em: 02 jan. 2013.

MAINARDES, J. Abordagem do ciclo de políticas: uma contribuição para a análise de políticas educacionais. Educação \& Sociedade, Campinas, v. 27, n. 94, p. 47-69, jan./abr., 2006.

Análise de políticas educacionais: breves considerações teórico-metodológicas. Contrapontos, Itajaí, v. 9, n. 1, p. 4-16, jan./abr., 2009.

GANDIN, L. A. A abordagem do ciclo de políticas como epistemetodologia: usos no Brasil e contribuições para a pesquisa sobre políticas educacionais. In: TELLO, C.; ALMEIDA, M. L. P. Estudos epistemológicos no campo da pesquisa em política educacional. Campinas: Mercado de Letras, 2013. p. 143-167

NATIVIDADE. Edital n. 01/2012, de 27 fev. 2012. Edital de Processo Seletivo Simplificado n. 001/2012. Disponível em: 〈http://www.idecan.org.br/concursos/53/1.pdf >. Acesso em: 02 jan. 2013.

NOVA IGUAÇU. Edital $n^{\circ}$ 001/2012, 20 de abr. 2012. Edital de concurso público $\mathbf{n}^{\mathbf{o}}$ 029/CEPUERJ/2012. Disponível em:

<http://www.agrobase.com.br/concursos/2012/concurso-prefeitura-nova-iguacu/ >Acesso em: 02 jan. 2013.

PETRÓPOLIS. Edital n.01/2011, de 10 dez. 2011. Concurso Público para Provimento de Cargos no âmbito da Prefeitura Municipal de Petrópolis - PMP. Disponível em:

Revista de Ciências Humanas | FW | v. 15 | n. 24 | p. 33-46 | Jul. 2014

Recebido em: 15 abr. 2014

Aceito em: 28 jul. 2014 
<http://200.150.155.210/pmp2011/Divulgacao/Edital\%20PMP_PMP.pdf >. Acesso em: 02 jan. 2013.

QUEIMADOS. Edital n.029/CEPUERJ/2012, 10 dez. 2012. Edital de concurso público no 029/CEPUERJ/2012. Disponível em: <http://www.pciconcursos.com.br/concurso/prefeiturade-queimados-rj-203-vagas>. Acesso em: 02 jan. 2013.

RIO DE JANEIRO. Lei 5597, 21.12.2009. Institui o Plano Estadual de Educação- PEE/RJ e dá outras providências. Diário oficial do estado do Rio de Janeiro, Rio de Janeiro, R.J. 21.12.2009. Disponível em:

<http://www.imprensaoficial.rj.gov.br/portal/modules/content/index. php?id=21>. Acesso em: 20 jun. 2013.

. Edital SMA nº11, 28 de maio 2012. Edital SMA no 111. Disponível em: <http://www.pciconcursos.com.br/concurso/prefeitura-do-rio-de-janeiro-rj-100-vagas-661>. Acesso em: 02 jan. 2013.

Edital SMA nº170, 26 de out. 2012. Edital SMA $\mathbf{n}^{\mathbf{0}}$ 170. Disponível em: <http://adaoblogado.blogspot.com.br/2012/10/edital-sma-n170-de-26-de-outubro-de.html>. Acesso em: 02 jan. 2013.

Edital Professor II 2013,18 mar. 2013. Edital SMA Nº5. Disponível em: <http://fjg.rio.rj.gov.br/publique/media/EDITAL_PROFESSOR_II_2013_PUB.pdf〉. Acesso em: 05 abr. 2013.

SÃO GONÇALO. Edital 003/PMSG/RJ, 15 de abr. de 2011. Edital $\mathbf{n}^{\mathbf{0}}$. 003/PMSG/RJ. Disponível em: <http://www.pmsg.rj.gov.br/diario/2011_06_30.pdf>. Acesso em: 02 jan. 2013.

SERAFIM, M. P.; DIAS, R. D. B. 2012. Análise de política: uma revisão da literatura. Cadernos Gestão Social, v. 3, n. 1, p. 121-134, jan./ jun. 2012.

SHIROMA, E. O.; CAMPOS, R. F.; GARCIA, R. M. C. Decifrar textos para compreender a política: subsídios teórico-metodológicos para análise de documentos. Perspectiva, Florianópolis, v. 23, n. 2, p. 427-446, jul./dez. 2005.

SOUZA, Celina. Políticas Públicas: uma revisão de literatura. Sociologias, v. 8, n.16, p. 2045, jul./dez., 2006.

. "Estado do campo" das políticas públicas no Brasil. Revista Brasileira de Ciências Sociais, v. 18, n. 51, p. 15-20, fev. 2003.

Revista de Ciências Humanas | FW | v. 15 | n. 24 | p. 33-46 | Jul. 2014

Recebido em: 15 abr. 2014

Aceito em: 28 jul. 2014 